\title{
Emotional Impact of Participation in an Intergenerational Service-Learning Course
}

\author{
Lori R. Kogan (Corresponding author) \\ Colorado State University, College of Veterinary Medicine \& Biomedical Sciences, \\ Department of Clinical Sciences, Fort Collins, CO, USA \\ Tel: 1-970-491-7984; E-mail: lori.kogan@colostate.edu
}

\section{Regina M. Schoenfeld-Tacher}

North Carolina State University, College of Veterinary Medicine, Molecular and Biomedical Sciences, Raleigh, NC, USA

Tel: 1-919-513-6096; E-mail: rmschoen@ncsu.edu

Peter W. Hellyer

Colorado State University, College of Veterinary Medicine \& Biomedical Sciences, Department of Clinical Sciences, Fort Collins, CO, USA

Tel: 1-970-297-4283; E-mail: peter.hellyer@colostate.edu

\author{
James A. Oxley \\ Independent Researcher, Measham, Swadlincote, United Kingdom, DE12 71Q \\ E-mail: james_oxley1@hotmail.com
}

Mark Rishniw

Veterinary Information Network, Davis, CA, United States.

Tel: 1-916-275-1650; E-mail: mrishniw@vin.com

Received: April 24, 2019 Accepted: May 15, 2019 Published: May 16, 2019

doi: 10.5296/ire.v7i2.14794 URL: https://doi.org/10.5296/ire.v7i2.14794 


\section{Abstract}

Service-learning offers numerous benefits to students, yet there is minimal research exploring the immediate impact of service-learning on students' emotive state. Given the prevalence of stress, depression and anxiety in college students, this area of research carries important implications. This paper investigates the emotional impact of participation in an intergenerational service-learning course on college students' moods. In the course investigated, students were responsible for providing direct services related to pet care to low-income elderly persons, and individuals with disabilities. Students were asked to track their moods before and after each interaction with a pet owner using a mobile application. They were also required to write reflection papers about their experiences, views, and insights gained over the course of the semester. Using the mood tracking application, participants reported improved mood after visiting clients and their pets when compared to before their visit. Students' personal reflection essays supported this trend in mood change. While it was not possible to determine whether the observed gains were due to interactions with the elderly or their pets, intergenerational service-learning courses represent a possible avenue for ameliorating mental health issues among college students.

Keywords: Service-learning, Intergenerational, Human-animal bond, Mood, Wellbeing

\section{Introduction}

This paper illustrates an example of a service-learning course and an innovative way to measure the emotional impact of the activity on participating students. While there is a growing body of literature discussing the effect of service-learning on students' perceptions and views of the world, there is minimal research exploring the immediate impact on students' emotive state. Yet, the ability to improve mood carries important implications, especially for individuals who are often stressed, anxious or depressed.

Students at universities are seeking counseling services at higher rates than ever before. Between 2009/2010 and 2014/2015 institutional enrollment grew by 5.6\%, yet the number of students seeking university counseling services increased by $29.6 \%$. Anxiety is the most common presenting concern of students seeking counseling services $(47.3 \%)$, followed by depression (40.1\%) (Center for Collegiate Mental Health [CCMH], 2015). Unfortunately, as the need for services continues to increase, many counseling center budgets remain stagnant, leading to fewer available clinicians and increased unmet need (Novotney, 2014).

These factors warrant an exploration of innovative methods that can potentially alleviate students' mental health issues. This paper explores the role service-learning courses may play in influencing students' moods. In this paper, we first discuss current research on service-learning courses in general and then describe a unique service-learning experience offered at a western university. By using a mobile self-report application to track mood, we analyze the impact of service-learning sessions on students' moods. We provide additional context related to longer-term changes through the exploration of student reflection papers and conclude with suggested next steps.

Service-learning (SL) is a form of community-based education that balances service and learning (Bringle et al., 2004; Hood, 2009). Service-learning combines formal coursework 
with community service to promote specific academic learning objectives and respond to community-identified needs (Eyler \& Giles, 1999). The focus on balance between student learning and a community's need for service is a key characteristic that distinguishes SL from other forms of education (Coe et al., 2015). Service-learning experiences have been shown to improve students' academic performance (Zacherman \& Foubert, 2014) and enhance critical thinking skills (Pike, 2004), as well as increase the likelihood of disadvantaged students successfully graduating (Kuh, 2009).

Intergenerational service-learning is a specific instance of SL, where members of different age cohorts work together to achieve personal or academic goals. It can offer college students an opportunity to interact directly with older adults, and may reduce negative perceptions and myths about aging populations (Kalisch et al., 2013). Intergenerational SL can encourage students to choose careers in the field of aging (Horowitz et al., 2010). As the median age of the US population continues to increase, there is a growing demand for people who want to work with older adults, and therefore, intergenerational service-learning courses are an important component in many academic programs (Karasik, 2013).

Pets Forever - Supporting the Life-long Bond, at Colorado State University offers an intergenerational service-learning course. The goal of the Pets Forever program is to preserve the human-animal bond by helping low-income elderly and disabled residents maintain ownership of their pets for as long as possible while improving the health and well-being of these pets and owners. Pets Forever's primary mission is the provision of direct services to clients and their pets. The direct service, such as dog walking and litter box cleaning, is provided by students enrolled in the service-learning course.

The course is a three credit, advanced level undergraduate class. Enrolled students come from all departments within the university. The students are required to complete an average of 5 hours of direct service each week. They are able to select the clients and pets with whom they would like to work. Students maintain the same routine and clients throughout the course; thereby enabling them to establish relationships with both the clients and their pets. Most students visit 3-4 clients each week. In addition to their service, all students are required to complete a reflection paper that summarizes their experiences, thoughts, and insights gained from the class (Figure 1). These reflections help students explore their changing perceptions of the elderly, and their unique experiences with each client.

\section{Materials and Methods}

To assess students' moods before and after each service session, students in the Pets Forever class during the Spring and Fall 2015 semesters were asked to provide mood data using a mobile mood app (Inexika, 2016) before and after each service session. Additionally, to assess any longer-term impact of the service work, students' reflection papers were qualitatively examined for general themes.

The mood app used in the current study was IMoodJournal (available on Apple and Android). The app allows people to easily track their mood by choosing one of ten options to denote their current mood ( 1 = "couldn't be worse", 10 = "insanely great"). Notes can be added to each tracked mood (Figure 2). Students were instructed to add the words "before" or "after" to each mood recorded to determine if the data entry was done prior to or after a service 
session. Students who entered data for at least $80 \%$ of their service sessions were able to substitute this assignment for a final writing assignment. Participation in the tracking component was voluntary and students could stop participating at any time. The study was reviewed by Colorado State University's Research Integrity and Compliance Review Office and granted exempt status (\#334-18H). Therefore, students were informed about the study both verbally and in writing (in the syllabus), and consent was obtained by virtue of survey completion.

Mood data was analyzed with IBM SPSS (Version 23), to determine if students' moods changed from pre-visit to post-visit. A signed-rank test was chosen for statistical analysis due to the nature of the data (integer data of a somewhat limited scale and not normally distributed) with a significance level set at $p<0.05$. The raw data supporting the conclusions of this manuscript will be made available by the authors, without undue reservation, to any qualified researcher.

\section{Results}

\subsection{Mood Changes}

Twenty-two students participated in spring 2015 (5 males, 17 females) and 21 students participated in fall 2015 (6 males, 15 females). Some students completed both the spring and fall course so the total number of unique participants was 43. A signed-rank test found no statistical differences between semesters or gender, allowing all student data to be combined for analyses. The assessment of median differences of mood before and after visits found the distribution was significantly different, with after service session scores higher than before service session scores. The median score for mood before service was 7.0 and it was 8.0 after service $(p<0.000)$. Students reported feeling happier after service sessions.

\subsection{Long-Term Impact}

Upon analysis of the written reflection papers, a number of themes emerged from the data. These appear to demonstrate the broader, long-term impact of the course on students' views of the world.

\subsubsection{Perspective}

Many students wrote about their personal growth through the experience, gaining a new perspective on the problems in their own lives, often recognizing these problems were not as big as they had thought they were.

"Suddenly all of my daily problems seem trivial and I find myself just giving thanks"

"I have come to the realization that there are numerous people in the world less fortunate than I am, and Pets Forever has opened my eyes to how lucky I am to have the life that I have."

\subsubsection{View of the Elderly}

For some students, this experience has changed how they view aging. 


\section{Macrothink}

International Research in Education

ISSN 2327-5499

2019, Vol. 7, No. 2

"I used to think that older people were so different, but I now realize how much in common I have with many of my clients."

\subsubsection{Development of Relationships}

Students find they easily connect and form close relationships with their clients.

"Not only did I get to know some of my clients on a personal basis, a lot of the time, they made my day much better than how it was going before I showed up at their houses."

"It shocked me when my clients took such an interest in my life. To see them actually want to know about me and the things going on with me was unexpected."

\subsubsection{Making a Difference}

Many students become excited to witness how they are able to make a difference for those they serve.

"The amazing feeling I receive by helping make people happy is something I have never felt before. It is an addictive feeling and now that I have experienced it I never want it to go away."

"When I thought of helping people, I would always think that I had to do something drastic to change their life in a positive way. Now I realize that the little things can make the biggest differences."

\section{Conclusion}

The results of this study suggest that providing service-learning improves students' moods. There was a significant increase in students' moods before and after service sessions as measured by a mood mobile app. Students' reflection papers also provided evidence to support this positive impact.

The sentiments and experiences of these students are not unique; other studies have reported similar positive results. Dorfman, Murty, Ingram, and Evans (2003) for example, found college students report positive companionship, social stimulation and improved quality of life after participating in service-learning. Other service-learning studies have noted an increased interest among students for working with older adults (Brown \& Roodin, 2001; Gutheil et al., 2006; Kolb, 2008) as well as positive personal growth, increased empathy, decreased fear about their own aging, and feelings of empowerment (Ames \& Diepstra, 2006; Dorfman et al., 2004). Several students from this study noted that involvement in service-learning involvement comprised one of their best college experiences.

The ability to alter perceptions of the elderly and gain feelings of confidence and empowerment are powerful impacts of a service-learning course. Additionally, the ability to impact students' day-to-day mood is also a valuable tool. Universities continue to struggle with ways to meet the growing psychological needs of their students with limited resources. Therefore, anything that is shown to improve students' mood is worthy of further exploration. It appears that service-learning experiences might offer an additional, non-traditional intervention for helping students' moods.

The unique nature of this service-learning course offers another potential explanation for the 
improved mood and overall positive impact. The students not only engaged with older people, but part of their service included interacting with pets. Numerous studies have found that interacting with animals offers emotional, physical and psychological benefits (Bao \& Schreer, 2016; Kanat-Maymon et al., 2015; McConnell et al., 2011). In particular, walking dogs has been shown to improve well-being (Andreassen et al., 2013; Antonacopoulos \& Pychyl, 2014), perhaps due to the companionship they provide or the actual exercise (Higgins et al., 2013; Johnson \& Meadows, 2010). Regardless of why interacting with animals appears to offer so many benefits, the fact that this service-learning course incorporated both people and animals offers the opportunity to further explore the specific aspects of this service-learning that led to positive mood changes.

The current study is not without limitations. All participants completed the same service-learning course. It is unknown whether the results may be due to a unique attribute of the course assessed, such as the fact that animals were involved, or if these results would generalize to other service-learning courses. It is also unknown if the fact that it was an intergenerational service-learning course influenced the effects on students. Additionally, the population assessed consisted primarily of women; more research into how student gender might influence the effect of service-learning is warranted. Lastly, the mood data consisted of students' self-report and although students were asked to complete their mood rating immediately before and after each service session, there were likely times in which the mood recording was delayed. Further studies could be designed to more closely track mood data entry times as they relate to service provided.

In summary, results of this study suggest that service-learning offers both immediate positive effects in terms of mood elevation, and longer term positive changes in perspective and world views. As schools search for ways to support students' psychological health, service-learning courses appear to be one innovative solution.

\section{Acknowledgment}

The authors would like to acknowledge the contributions of Pets Forever volunteers and clients in generating the data for this study.

\section{References}

Ames, N., \& Diepstra, S. A. (2006). Using intergenerational oral history service-learning projects to teach human behavior concepts: a qualitative analysis. Educational Gerontology, 32(9), 721-735. https://doi.org/10.1080/03601270600835447

Andreassen, G., Stenvold, L. C., \& Rudmin, F. W. (2013). "My dog is my best friend": health benefits of emotional attachment to a pet dog. Psychology \& Society, 5(1), 6-23.

Antonacopoulos, N. M. D., \& Pychyl, T. A. (2014). An examination of the possible benefits for well-being arising from the social interactions that occur while dog walking. Society \& Animals, 22(5), 459-480. https://doi.org/10.1163/15685306-12341338

Bao, K. J., \& Schreer, G. (2016) Pets and happiness: examining the association between pet ownership and wellbeing. Anthrozoös, 29(2), 283-296. https://doi.org/10.1080/08927936. 2016.1152721

Bringle, R. G., Phillips, M. A., \& Hudson, M. (2004). The measure of service-learning. 
American Psychological Association: Washington, DC, WA.

Brown, L. H., \& Roodin, P. A. (2001). Service-learning in gerontology: an out of classroom experience. Educational Gerontology, 27(1), 89-103. https://doi.org/10.1080/03601270 1750069067

Center for Collegiate Mental Health (CCMH). (2015) Annual Report (Publication No. STA 15-108). University Park, PA.

Coe, J. M., Best, A. M., Warren, J. J., McQuistan, M. R., Kolker, J. L., \& Isringhausen, K. T. (2015). Service-learning's impact on dental students' attitude towards community service. European Journal of Dental Education, 19(3), 131-139. https://doi.org/10.1111/eje.12113

Dorfman, L. T., Murty, S., Ingram, J. G., \& Evans, R. J. (2003). Incorporating intergenerational service-learning into an introductory gerontology course. Journal of Gerontological Social Work, 39(1-2), 219-240. https://doi.org/10.1300/J083v39n01_18

Dorfman, L. T., Murty, S. A., Ingram, J. G., Evans, R. J., \& Power, J. R. (2004). Intergenerational service-learning in five cohorts of students: is attitude change robust? Educational Gerontology, 30(1), 39-55.

Eyler, J., \& Giles, D. E. (1999). Where's the service in service-learning?. Jossey-Bass: San Francisco, CA.

Gutheil, I. A., Chernesky, R. H., \& Sherratt, M. L. (2006). Influencing student attitudes toward older adults: results of a service-learning collaboration. Educational Gerontology, 32(9), 771-784. https://doi.org/10.1080/03601270600835470

Higgins, J. W., Temple, V., Murray, H., Kumm, E., \& Rhodes, R. (2013). Walking sole mates: dogs motivating, enabling and supporting guardians' physical activity. Anthrozoös, 26(2), 237-252. https://doi.org/10.2752/175303713X13636846944286

Hood, J. G. (2009). Service-learning in dental education: meeting needs and challenges. Journal of Dental Education, 73(4), 454-463.

Horowitz, B. P, Wong, S. D., \& Dechello, K. (2010). Intergenerational service learning: to promote active aging, and occupational therapy gerontology practice. Gerontology \& Geriatrics Education, 31(1), 75-91. https://doi.org/10.1080/02701960903578345

Inexika (2016). iMoodJournal [mobile app]. Available from http://www.inexika.com/imood Johnson, R. A., \& Meadows, R. (2010). Dog walking: motivation for adherence to a walking program. Clinical Nursing Research, 19(4), 387-402. https://doi.org/10.1177/1054773810373 122

Kalisch, H. R., Coughlin, D. R., Ballard, S. M., \& Lamson, A. (2013). Old age is a part of living: student reflections on intergenerational service-learning. Gerontology \& Geriatrics Education, 34(1), 99-113. https://doi.org/10.1080/02701960.2012.753440

Kanat-Maymon, Y., Antebi, A., \& Zilcha-Mano, S. (2015). Basic psychological need fulfillment in human-pet relationships and well-being. Personality and Individual Differences, 92, 69-73. https://doi.org/10.1016/j.paid.2015.12.025

Karasik, R. J. (2013). Reflecting on reflection: capitalizing on the learning in intergenerational service-learning. Gerontology \& Geriatrics Education, 34(1), 78-98. 
Kolb, P. (2008). Interest of racially and ethnically diverse social work students in gerontological social work. Educational Gerontology, 34(10), 907-922. https://doi.org/10.1080/03601270802129219

Kuh, G. D. (2009). What student affairs professionals need to know about student engagement. Journal of College Student Development, 50(6), 683-706. 10.1353/csd.0.0099

McConnell, A. R., Brown, C. M., Shoda, T. M., Stayton, L. E., \& Martin, C. E. (2011). Friends with benefits: on the positive consequences of pet ownership. Journal of Personality and Social Psychology, 101(6), 1239-1252.

Novotney, A. (2014). Students under pressure. Monitor on Psychology, 49(8). [Online] Available from: http://www.apa.org/monitor/2014/09/cover-pressure.aspx (05/04/2019)

Pike, G. R. (2004). The influence of fraternity or sorority membership on students' college experiences and cognitive development. Research in Higher Education, 41(1), 117-139. https://doi.org/10.1023/A:1007046513949

Zacherman, A., \& Foubert, J. (2014). The relationship between engagement in cocurricular activities and academic performance: Exploring gender differences. Journal of Student Affairs Research and Practice, 51(2), 157-169. https://doi.org/10.1515/jsarp-2014-0016

\section{Appendix}

Appendix 1. Figures

\section{Figure Captions}

\section{Service Learning Reflection Paper}

You will be expected to write a reflection paper (submit via course LMS), summarizing your experiences and thoughts about your service. This paper can focus on one client or your overall reflections of working with this vulnerable population. The reflection should be approximately 4 pages (typed, double spaced). Your grade will be based on the following:

- The reflection should be a true reflection of your experience with Pets Forever, rather than just a recap/summary of what happened.

- The reflection should be in context of the material discussed in class and the course learning objectives.

- Personal feelings are encouraged, but professional writing, proper grammar, punctuation, spelling are all expected.

- The reflection should demonstrate your ablity to synthesize the experiences gained during the service learning component of class.

Your reflection paper can address any one or more of the following questions. If you have completed a reflection paper in a previous semester, please focus on a different question/topic or see the instructor for additional ideas for reflection topics. This writing exercise is meant to stimulate your own personal reflection, so please take some time to think about the questions before you begin to write.

- In general, what are the most important things that you have learned through your experiences with Pets Forever program?

- Discuss your experiences with one particular client and how this has changed your perceptions.

- How did your experiences affect the way you think about the issues and/or clients that Pets Forever program deals with?

- What have you learned about social inequality through your service work?

- What have you personally learned about yourself from your service this semester?

Figure 1. Assignment instructions for reflection paper on inter-generational service learning project 


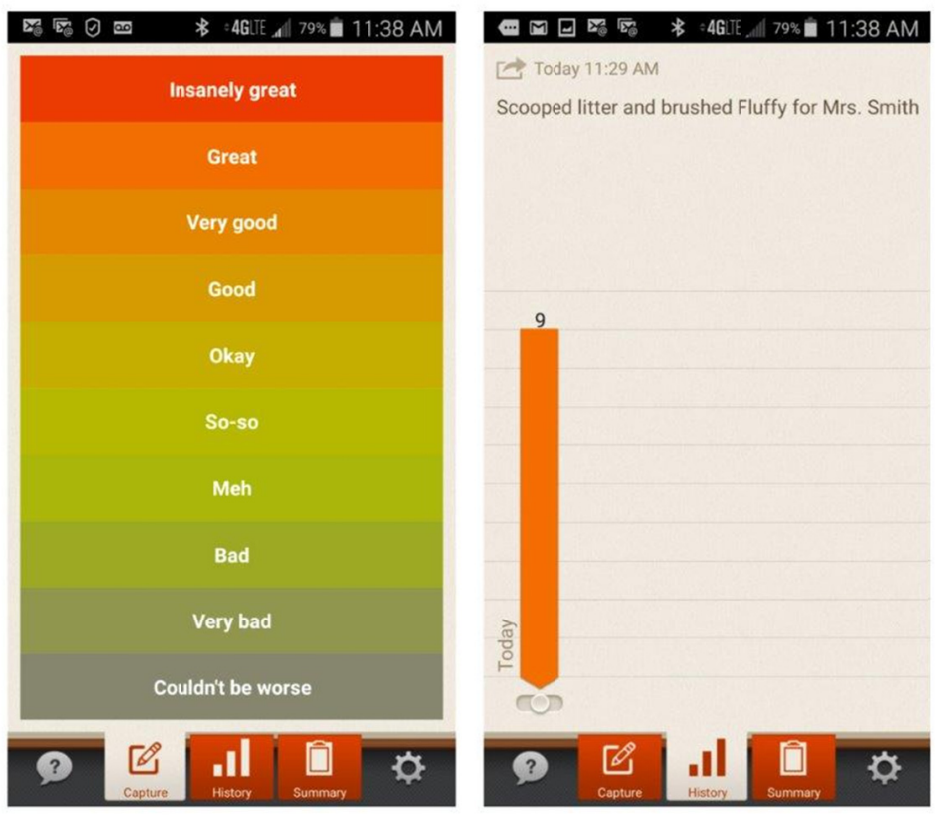

Figure 2. Screenshots from iMood Journal, showing rating system (left) and tracking views (right) used in the study

\section{Copyright Disclaimer}

Copyright reserved by the authors.

This article is an open-access article distributed under the terms and conditions of the Creative Commons Attribution license (http://creativecommons.org/licenses/by/3.0/). 